\title{
Discourse Marker Clusters in the Classroom Discourse of Native and Non-Native EFL Teachers
}

\author{
Gloria Vickov and Eva Jakupčević \\ Faculty of Humanities and Social Sciences, University of Split \\ Split, Croatia
}

\begin{abstract}
The present study focuses on the DM cluster use of three native and three non-native (Croatian) teachers of English working in Croatia, based on an analysis of a corpus of their talk in the classroom. As essential elements of fluent and coherent speech, discourse markers (DMs) are ubiquitous in discourse, with numerous uses in the foreign language classroom. A specific feature of DM use is the tendency of speakers to combine them, i.e. use them in clusters. The quantitative analysis of the corpus of teacher talk has revealed that native and nonnative teachers differ in their use of DM clusters in classroom discourse. Native teachers use DM clusters significantly more frequently and with more diversity, while non-native teachers seem to be less flexible in their use. The qualitative analysis provides insight into the functions of the most frequent clusters in the speech of the teachers, pointing to a variety of valuable functions of these units in the classroom. The results indicate the need to bring DM cluster use to the attention of non-native teachers in the course of their training to enable them to make full use of the potential benefits of these units in their classroom discourse.
\end{abstract}

Keywords: discourse marker clusters; non-native teachers; native teachers; teacher talk

\section{Introduction}

Over the last few decades, discourse markers (DMs), words and phrases such as okay, well, you know and anyway, have become a popular research topic, at the same time managing to elude strict definitions and conclusive explanations (for a detailed theoretical overview see Maschler \& Schiffrin, 2015). In general, DMs are multifunctional linguistic units, syntactically independent from the rest of the utterance, principally non-propositional and semantically optional (Müller, 2005). They fulfil textual and interpersonal functions, providing support for discourse participants in interaction by directing them in choosing the right meaning out of all possible meanings (Aijmer \& Simon-Vandenbergen, 2011). This makes them an essential element of pragmatic competence (Müller, 2005), 
and insufficient and incorrect use of DMs may reduce communication effectiveness and impede interpersonal and intercultural interaction (Lahuerta Martínez, 2004; Lam, 2010). One interesting aspect of DM use, which has been somewhat overlooked in research to date (Cuenca \& Crible, 2019), is the tendency of speakers to use these units in combinations, or clusters, especially in spoken, spontaneous conversations and in lectures (Amador Moreno, O’Riordan, \& Chambers, 2006; Flowerdew \& Tauroza, 1995; Pons Bordería, 2018).

The present study was undertaken in an attempt to provide a comparison between the way native and non-native teachers in Croatia use DMs, focusing on a specific and pervasive feature of DM use - DM clusters. The results of this study are expected to shed more light on the way native and non-native teachers combine DMs to fulfil important communicative, interpersonal and organizational functions within FL classroom settings. This comparative study will hopefully contribute to the limited existing knowledge of DM cluster use in native and non-native FL teacher talk.

\section{Literature Review}

\subsection{Discourse Markers in the Language Classroom}

The importance of DMs for both teachers and learners in the FL classroom cannot be overstated. DMs have been shown to facilitate the comprehension of lectures (Flowerdew \& Tauroza, 1995; Jung, 2006), in addition to helping teachers lead students through discourse, hold their attention, announce a change in activity and signalize the beginnings and ends of lesson phases, making sure learners do not lose their way in the discourse (Walsh, 2013). In other words, appropriate DM use can help students to better understand both the teacher's language and the demands of the classroom context. In addition, DMs play a role in establishing interpersonal relationships and reducing social distance between the teacher and the students, thus stimulating the creation of shared space and a potentially better atmosphere for active participation (Othman, 2010; Walsh, 2006). Language teachers are not only the managers of classroom discourse but also an important source of input for their students, and modelling the target language is one of their main tasks in the classroom (Walsh, 2006). Thus, by using DMs in their speech, teachers are making their language and purpose more comprehensible, at the same time demonstrating DM use for their students and, finally, creating a more inviting classroom environment.

Despite the recognized importance of FL teachers as managers of classroom discourse and key sources of language input for FL learners in pedagogical settings (Walsh, 2006), research reporting on the DM use of non-native FL teachers is rare. Similarly to the results of the abovementioned studies of nonnative speakers' use of DMs, the results of the existing studies of DM use of nonnative FL teachers also indicate varying trends when it comes to DM use in the classroom. While some studies point to the teachers' inappropriate use of DMs (Khazaee, 2012; Shahbaz, Sheikh, \& Ali, 2013), others demonstrate more positive patterns of use. For example. Chapetón Castro (2009) describes an example of one non-native teacher's successful use of DMs to structure his talk in the 
classroom. Furthermore, a study of six Croatian EFL teachers (Vickov \& Jakupčević, 2017) has shown that, although they use just a narrow range of these units frequently, they use them strategically to structure classroom discourse and maintain interpersonal relationships in the classroom. However, what these studies have in common is that they exclusively focus on non-native teachers, without a comparison with their native counterparts which could provide more insight into what kind of a model non-native teachers are for their students when it comes to DM use.

\subsection{Discourse Marker Clusters}

As previously mentioned, DMs have been shown to commonly appear in clusters, which seem to be a typical characteristic of how these linguistic units are used (Lohmann \& Koops, 2016). According to Cuenca and Crible (2019, p. 175) "two or more DMs co-occur when they are contiguous and have partial or total scope over a discourse unit that they connectively relate to a previous segment or discourse unit." Research of speakers of different L1s has confirmed the prevalence of these units in speech (for a more detailed overview, see Cuenca \& Crible, 2019). For example, in the French-English corpus (DisFrEn) analysed by Crible and Cuenca (2017), the authors found that $20 \%$ of all DMs appeared as a part of a DM sequence. Maschler (2002) found a high frequency of DM clusters in Hebrew-English bilingual talk and noticed the tendency of DM to cluster at verbal activity boundaries. Cuenca and Marín (2009) focused on the combinations of DMs in Catalan and Spanish, finding that they are ubiquitous in both languages, carrying out important functions such as indicating transition places and performing as phatic cues.

Although it is clear that DMs tend to cluster in speech, there is still no agreement as to why this happens. On the one hand, according to Flowerdew and Tauroza (1995), if we see DMs as 'empty', or void of any semantic meaning, the use of more than one marker at a time is likely to increase processing time and thus provide a greater chance for improved comprehension. Thornbury and Slade (2006) similarly claim that the main use of DM clusters is to help buy time for speakers, and Aijmer (2004) also asserts that the tendency of markers to combine suggests that they have little function in themselves. They thus represent one of the many dysfluencies occurring in natural speech as a consequence of the demands of 'on-line' communication requiring instant cognitive processing, which can present great demands on the attention and memory of interlocutors (Bortfeld, Leon, Bloom, Schober, \& Brennan, 2001; De Klerk, 2005). This makes DM clusters important tools which provide the speakers with time to plan what to say next or to choose a new orientation of discourse (Aijmer, 2004).

However, if we view DMs as carrying meaning, their clusters might serve as a more emphatic indication of whether or not a new mental model should be invoked (Fleischman \& Yaguello, 2004). In that case, the co-occurrence of markers is not a redundancy, in that each DM in a cluster still retains its function while working together in combination. This has been confirmed by Fairbanks (2016) in his study of DMs in the Ojibwe language, in which DMs have been found to commonly cluster together with each particle typically contributing some meaning or function to the cluster. As the meanings of the individual 
markers remain obvious in clusters, speakers can use "tailor-made combinations" for specific contexts (Fairbanks, 2016, p.149).

Whether DM clusters serve purely to facilitate processing or to create joint meaning on a global level, existing research gives support to the idea that discourse marker clusters are indeed highly relevant for speakers.

\subsection{Discourse marker clusters and non-native FL teachers}

The significance of DM clusters for native speakers suggests that these combinations would also be useful for non-native speakers. However, there is insufficient research focusing on DM clusters in the speech of language learners or non-native teachers, with this topic only mentioned in some studies. For example, in her comparison of native (London-Lund Corpus of Spoken English) and non-native (Swedish) speakers of English, Aijmer (2004) touches upon their use of DM clusters. She found that both native and non-native speakers use DM clusters to gain thinking and planning time, make a new start and reformulate what they have just said. However, only the native speakers used them to reinforce the phatic function of the markers, which implies that non-native speakers might not have a full understanding of all of their functions. As for the classroom context, the research is even scarcer. A rare example is a study by Amador Moreno et al. (2006), in which the authors briefly state that DM clusters are present in the language of native and non-native teachers of French and Spanish, despite the limited number of individual DMs and their functions used by all four groups of teachers in the study.

Taking into account the features of DM clusters described above, if DM clusters can be used to make the speaker's intended meaning more salient, they could support teachers in making their language more explicit and avoiding misunderstandings, which would be especially beneficial in classrooms where a foreign language is taught. The fact that DM clusters provide planning time for the speakers and help them emphasise that a new topic is being introduced (Aijmer, 2004) would also make them an invaluable tool for both native and nonnative language teachers, making their language clearer and helping their students to stay focused on the message. Non-native FL teachers would be expected to additionally benefit from their use given that communication in a foreign language can cause a lot of stress for non-native speakers who are simultaneously trying to express their ideas and are doing so in a language that is not their mother tongue (Aijmer, 2004).

In conclusion, although it is obvious that the use of DM clusters plays an important role in the speech of both native and non-native speakers of a language, the dearth of existing research makes it difficult to draw any useful conclusions on the role these units might play in the non-native teachers' discourse in the FL classroom.

\section{The present study}

The present study aims to provide insight into how native and non-native teachers of English as a foreign language (EFL) in Croatia use DM clusters in their speech in the classroom. Our goal is to find out whether there were any 
differences in how native and non-native EFL teachers use DM clusters in comparable classes with upper-intermediate students. Moreover, we want to determine the main functions of the most frequent clusters in classroom discourse to provide more insight into the functions of DM clusters in this specific context.

More specifically, our study aims to answer the following research questions:

1. Are there any differences between the frequencies of DM clusters in the talk of native and non-native EFL teachers working in Croatia?

2. Are there any differences between the numbers of unique DM clusters used by native and non-native EFL teachers working in Croatia?

3. What are the most commonly used DM clusters and their functions in the talk of native and non-native EFL teachers?

A mixed-method approach will be used to answer the research questions. A small corpus of teacher talk will be analysed, and the first two questions will be answered using a preliminary, small-scale quantitative analysis. The third question will be answered using a qualitative approach, with examples of DM clusters used by the teachers analysed in context.

\section{Methodology}

\subsection{Participants}

The participants in the present study were six EFL teachers working in Croatia, three native (one Canadian, two Australian, referred to as NT1, NT2 and NT3) and three non-native speakers of English (L1 speakers of Croatian, referred to as NNT1, NNT2 and NNT3), all with over 8 years of teaching experience (Table 1). All of the teachers hold a language teaching degree. The non-native teachers were highly proficient speakers of English (level C2) and the native teachers had all been living and working in Croatia for over 10 years. Although the six teachers worked in different institutions, they all taught upper-intermediate to advanced students, and a communicative approach focusing on speaking activities was used in all recorded lessons.

Table 1: Information about the teachers.

\begin{tabular}{|c|c|c|}
\hline Teacher & Age & $\begin{array}{c}\text { Work experience } \\
\text { (years) }\end{array}$ \\
\hline NS1 & 36 & 12 \\
\hline NS2 & 40 & 15 \\
\hline NS3 & 38 & 10 \\
\hline NNS1 & 33 & 8 \\
\hline NNS2 & 31 & 8 \\
\hline NNS3 & 33 & 10 \\
\hline
\end{tabular}

\subsection{Instrument}

The main instrument in the study is a corpus consisting of two subcorpora, one containing the speech of native and the other of non-native teachers. It is based on recordings made during lessons with upper-intermediate to advanced adult 
students (level B2 and higher). Between 65 and 90 minutes of classroom talk were recorded for each teacher, amounting to a total of 496 minutes of EFL classroom talk (Table 2).

The classes recording included a range of activities, largely focused on the students' spoken production. There were no specific differences when it came to the teaching approaches of the native and non-native teachers, as the method of teaching in all the classes, according to the teachers themselves, was based on the communicative approach.

The teachers and students gave their consent for the recording. The teachers recorded the classes themselves, without the presence of the authors, using a speech recorder placed on their desk to minimize interference and keep the classes as natural as possible.

Table 2: Length of the recording.

\begin{tabular}{|c|c|c|}
\hline Teacher & Session $\mathbf{1}$ & Session 2 \\
\hline NS1 & $43 \mathrm{~min}$ & $45 \mathrm{~min}$ \\
\hline NS2 & $45 \mathrm{~min}$ & $43 \mathrm{~min}$ \\
\hline NS3 & $28 \mathrm{~min}$ & $37 \mathrm{~min}$ \\
\hline NNS1 & $44 \mathrm{~min}$ & $38 \mathrm{~min}$ \\
\hline NNS2 & $40 \mathrm{~min}$ & $44 \mathrm{~min}$ \\
\hline NNS3 & $45 \mathrm{~min}$ & $45 \mathrm{~min}$ \\
\hline
\end{tabular}

\subsection{Analysis}

The recordings were transcribed using standard orthography and the transcripts were subsequently rechecked. The transcripts were then analysed in detail, and the occurrences of individual DMs were identified and coded. The analysis was first performed by one of the authors and later checked by the other author, with any differences in DM identification discussed and resolved. This identification primarily rests on Fung and Carter's (2007) framework of DM use in the pedagogical setting, grounded on Schiffrin's (as cited in Fung \& Carter, 2007) muti-dimensional model of coherence, which enables a functionally based account of the functions of these units in the classroom context. Their list of DMs has been supplemented, as needed, by those of other authors (e.g. Brinton, 1996; Swan, 2016), while keeping in mind the following three conditions that a linguistic element must fulfil to be considered a DM (Fuller, 2003):

1. It signalizes the relationship between preceding discourse and the discourse that follows.

2. The semantic relationship between elements remains the same if the element is removed.

3. The utterance remains grammatically untouched if the element is removed.

It was important to perform the analysis manually as words that act as DMs can often have other functions depending on the context. For example, in addition to 
acting as a DM, so can be used as an intensifier or to avoid repeating a previously mentioned phrase, among its many uses. After the coding of single DMs, the transcripts were analysed once more to count the occurrences of DM clusters. In the present research, we take a DM cluster to be any co-occurrence of two or more discourse markers in speech. Although Cuenca and Crible (2019) exclude some cases from the group, such as those with longer pauses between the elements or cases of re-starts and repetitions, in order to simplify our analysis we have counted all co-occurrences of either two or more different DMs and sequential repetitions of the same DM as DM clusters.

In order to answer the first two research questions regarding the differences between the DM cluster use of native and non-native teachers, a statistical analysis was performed using the RStudio software (R Core Team, 2013). More specifically, two independent samples t-tests were conducted to determine whether the differences between the frequencies of DM cluster use and the number of unique DM clusters employed in the speech of the two groups of teachers were significant. Due to the small sample, the quantitative analysis was seen as a basic, preliminary analysis to serve as an indication of potential directions for further research. Finally, with the aim of answering the third research question, a more extensive qualitative analysis of the functions of the most frequent DM clusters was performed. Instances of the five most frequent DM clusters were extracted from the corpus and analysed in context by determining their most common functions and patterns of use. Finally, examples of interesting instances of individual teachers' DM cluster use as well as longer DM clusters were also extracted for analysis.

\section{Results}

\subsection{Quantitative Analysis}

As shown in Table 3, our corpus of teacher talk contains 36597 words in total, relatively evenly distributed between the two subcorpora, with the native speaker subcorpus consisting of 18253 words and non-native one of 18344 words. There are 4155 instances of DM use in the corpus, with a frequency of 113.54/1000 words. The participants used 50 unique single DMs in total. Furthermore, there are 719 occurrences of DM clusters in the corpus, with an overall frequency of $19.64 / 1000$ words.

Table 3: Information about the corpora.

\begin{tabular}{|l|c|c|c|}
\hline & NS & NNS & total \\
\hline Number of words & 18253 & 18344 & 36597 \\
\hline Number of single DMs & 2403 & 1752 & 4155 \\
\hline Single DMs/1000 words & 131.65 & 95.51 & 113.53 \\
\hline Number of unique DMs & 34 & 35 & 50 \\
\hline Number of DM clusters & 525 & 194 & 719 \\
\hline DM clusters/1000 words & 28.76 & 10.58 & 19.64 \\
\hline Number of unique DM clusters & 301 & 113 & 372 \\
\hline DM clusters containing repetitions & 56 & 10 & 66 \\
\hline DM clusters containing more than two DMs & 109 & 13 & 122 \\
\hline
\end{tabular}

NS - native-speaker subcorpus, NNS - non-native speaker subcorpus 
In total, 372 different DM cluster combinations were used by the subjects. Interestingly, only 7 unique DM clusters appear more than 10 times in the corpus (Table 4). The non-native teachers used only two DM clusters on more than ten occasions, while the native teachers used five (Table 5).

Out of the total 719 individual occurrences of DM clusters, there are 66 instances (a little under 10\%) of clusters consisting of or containing repeated markers. The most frequently used repetitions are ok ok, yeah yeah, yes yes and alright alright (used in 10, 10, 6 and 5 instances, respectively). Moreover, there are 122 instances (or 17\%) of DM clusters consisting of three or more DMs in the corpus. The largest DM clusters found consist of 5 DMs (e.g. alright ok ok alright but, ok ah ok alright alright), and they usually contain repetitions.

Table 4: Ten most frequent DM clusters in the corpus.

\begin{tabular}{|c|c|c|c|}
\hline DM cluster & Occurrences & DM cluster & Occurrences \\
\hline ok so & 50 & ok ok & 10 \\
\hline and then & 46 & yeah yeah & 10 \\
\hline alright so & 28 & but then & 9 \\
\hline ok and & 12 & yeah but & 9 \\
\hline right so & 12 & yes so & 8 \\
\hline
\end{tabular}

Table 5: Five most frequent DM clusters per subcorpus.

\begin{tabular}{|c|c|c|c|}
\hline \multicolumn{2}{|c|}{ NS } & \multicolumn{2}{c|}{ NNS } \\
\hline DM cluster & Occurrences & DM cluster & Occurrences \\
\hline ok so & 37 & and then & 15 \\
\hline and then & 31 & ok so & 13 \\
\hline alright so & 24 & mhm yeah & 8 \\
\hline right so & 12 & ok alright & 6 \\
\hline ok and & 10 & ok but & 6 \\
\hline
\end{tabular}

NS - native-speaker subcorpus, NNS - non-native speaker subcorpus

Out of the 719 DM clusters that appeared in our corpus, native teachers used 525 (27.98/1000 words), while non-native teachers used 194 (10.63/1000 words) (Table 3). Native teachers thus used DM clusters almost three times more frequently than non-native teachers. In addition, native teachers used almost three times as many unique DM clusters than non-native teachers, with the two groups employing 301 and 113 unique markers, respectively (Table 3). The results of the independent samples t-test confirmed the relevance of these results, showing that there was a significant effect of group on the number of clusters used $(\mathrm{t}(4)=5.695, \mathrm{p}=.005)$, as well as on the number of unique clusters $(\mathrm{t}(2)=3.784, \mathrm{p}=.03)$. Thus, the native teachers in our sample used significantly more DM clusters and more unique DM clusters than non-native teachers. Finally, out of the 122 clusters consisting of more than two DMs, non-native speakers used only 13, while out of the 66 clusters containing repetitions, this group employed only 10.

The data for individual teachers (Table 6) show that non-native teachers used 9.45, 10.12 and 12.31 DM clusters/1000 words, i.e. they used DM clusters with 
similar frequencies. On the other hand, two of the native teachers (NT1 and NT3) used a comparable frequency of DM clusters (31.41 and 31.19 DM clusters/1000 words), while one, NT2, used DM clusters somewhat less frequently (22.35/1000 words), although still almost twice as much as the nonnative teachers. The results are similar when it comes to the number of unique DM clusters, with non-native teachers using 32, 41 and 58 unique clusters, while the differences among the native teachers are more expressed. Once again, NT1 and NT3 used similar numbers of unique clusters (121 and 134, respectively), while NT2 used only 80, but still more than the all of the non-native teachers in our corpus.

Table 6: Individual teachers' use of DM clusters.

\begin{tabular}{|c|c|c|c|c|}
\hline Teacher & $\begin{array}{c}\text { No of DM } \\
\text { clusters }\end{array}$ & $\begin{array}{c}\text { No of unique } \\
\text { clusters }\end{array}$ & $\begin{array}{c}\text { DMs } \\
\text { clusters/1000 } \\
\text { words }\end{array}$ & $\begin{array}{c}\text { Total No of } \\
\text { words }\end{array}$ \\
\hline NT1 & 220 & 121 & 30.41 & 7004 \\
\hline NT2 & 116 & 80 & 22.35 & 5190 \\
\hline NT3 & 189 & 134 & 31.19 & 6059 \\
\hline NNT1 & 65 & 41 & 12.31 & 5277 \\
\hline NNT2 & 46 & 32 & 9.45 & 4863 \\
\hline NNT3 & 83 & 58 & 10.12 & 8204 \\
\hline
\end{tabular}

\subsection{Qualitative Analysis}

The qualitative analysis of the corpus was performed by investigating the functions of the most frequent DM clusters used by the teachers in our corpus (Table 4) in context. Five DM clusters were used more than ten times in our corpus, which brings them into the focus of our qualitative analysis, together with some examples of individual teachers' DM use.

Okso

The most frequent cluster in our corpus is ok so, used by all six teachers in our study. Both constituent DMs in this cluster are useful and versatile units, commonly used in classroom talk (Fung \& Carter 2007; Othman, 2010). A common function of the cluster ok so in our corpus is to emphasize that a new topic is being introduced and to focus the listeners' attention to a new task. This is in line with the functions of these two markers as described in the literature, with $o k$ commonly used to open or close topics or as an attention-getter (Fung \& Carter, 2007; Othman, 2010), and with so contributing to this function by acting as a focusing device or a transition marker (Buysse, 2012). This is not only a recurrent function, but it is also a key one in classrooms where it is crucial to make sure that students are paying attention especially carefully at task transitions (Examples 1a-1b).

(1a) NNT2: $O \boldsymbol{k}$ so please open your notebooks, put the dates it's the $11^{\text {th }}$ of November.

(1b) NT1: Ok so tell me a little before we continue with the book, how was um your prom, so M. knows what to expect tonight. 
The discourse marker $o k$ is commonly used to acknowledge a response, which is another function relevant to the classroom as the acknowledgement forms the final part of the common tripartite pattern of pedagogic talk - initiation, response, feedback (Walsh, 2013). In combination with so, this function becomes acknowledgement and rewording of the student's response for emphasis or correction. In the following examples, the teachers acknowledge, reword and add to the answer (Example 1c) or ask a further question (Example 1d, with the question prefaced with another instance of so).

(1c) NNT1: Ok so I might join I may join I could join completely the same thing.

(1d) NT2: $O \boldsymbol{k}$ so the soldiers fought, so number one is?

The DM so can serve to introduce a question, a set of instructions or a summary (Müller, 2005). In the following examples, the addition of $o k$ before so acts as a method of focusing the attention of the listeners on the upcoming question (Examples 1e and 1f), instruction (Example 1g), or summary of relevant information (Example 1h). These are important points in the course of a lesson and the teachers use this cluster to make sure that students know that their attention is needed.

(1e) NT2: It says which of the following things can be mown, ok so what will you circle there?

(1f) NT1: Ok so are you allowed to uhm I don't know, depending on your subject, but are you allowed to use the internet for sources of information?

(1g) NNT2: $\boldsymbol{O} \boldsymbol{k}$ so class, let's ask B. some questions.

(1h) NT2: No, when we when we're talking about spawning we usually refer to fish, fish fish lay eggs ok so the literal meaning of spawn is to lay eggs.

\section{And then}

The second most frequent DM cluster in our corpus is and then, almost invariably used by our participants to express a result (Examples 2a and $2 \mathrm{~b}$ ) or a sequence. This sequence can either be temporal (Example 2c), refer to a sequence of instructions (Example 2d) or steps that need to be taken (Example 2e) or even, as in Example 2f, a sequence of gradations.

(2a) NT3: Yeah cause it seems it should be, but it- then you get something that would happen, that they would, someone gets clever and creative and they wanted to for whatever reasons try something new and then without testing it it gets sent to the market and then people are having these reactions and then they get sued they get huge things so it gets down to money.

(2b) NT2: Alright well well can you talk to me in English please and then I might be able to understand you

(2c) NNT1: Ok let's check this one and then you're all free to go.

(2d) NNT3: I don't think they're too expensive, they're like ten kunas maybe, this huge bag of marshmallows, and then you put them on a stick you 
put them on a stick and then you can just fry them fry them or whatever, they're good.

(2e) NNT3: I'll give you a minute to read these three sentences and then you have on the right one two three and the box you have to match a meaning of get in one two three with a sentence.

NNT3: Um anger is not strong enough, you have fury and then you have rage.

\section{Alright so}

The third most frequent DM cluster is specific because, as opposed to the first two (ok so and and then), which are used by all speakers, alright so is used (in 23 out of 28 instances) overwhelmingly by a single teacher, NT1. This indicates a personal preference of NT1 for this specific DM cluster, which we cannot contribute solely to the fact that he is a native speaker as this cluster is not used that frequently by the other two native speakers. In fact, NT1 uses the individual DM alright at the beginning of many of his turns, which is in line with Schleef's (2008) observation that speakers commonly show a preference for particular structural markers in their speech (e.g. ok, alright, right).

The functions of the cluster alright so are comparable to those of $o k$ so, which is unsurprising due to the similarity between the uses of the DMs alright and $o k$, with alright also acting as a focusing device or a marker of acknowledgement (Bangerter \& Clark, 2003). For example, this cluster is used to focus the attention of listeners on an explanation or elaboration of a previous statement (Examples $3 a$ and $3 b$ ) or a question (Example 3c)

(3a) NT1: Alright so do you see the point always the answers were if you look at it the answers were constantly given (...)

(3b) NT2: Alright so it means that to move quickly it's a very um precise fluttering, darting movement, ok?

(3c) NNT1: Alright so how did it go?

Additionally, alright so is used to acknowledge the response to a student's statement and add a comment or an evaluation of the previous utterance (Examples 3d and 3e).

(3d) NT3: In the country ok clean fresh air, alright so the exception to the rules-

(3e) NT1: Alright so it's just to occupy him, right?

\section{Ok and and right so}

The fourth and the fifth most frequent clusters in our corpus were both used 12 times by our teachers. The first one, ok and, is used to acknowledge a response and to preface an elaboration or a follow-up question (examples $4 a-4 b$ ), while in example $4 \mathrm{c}$ this cluster is used to acknowledge the previous turn of the student (in this case, the student's reading of a text) and continue the task with another student. Finally, in example $4 \mathrm{~d}$ the teacher uses $o k$ and to introduce a digression, with the cluster acting as an indicator that the question which follows is connected to the previous discourse. 
(4a) NNT2: $O k$ and food can be spoilt as well, right.

(4b) NT3: Ok and why, what's the main impetus, what do you think the klinci [kids] as we call them, the little kids, the little school kids, why do klinci start smoking so early?

(4c) NT3: $O k$ and please next, with the animal right legal protest?

(4d) NT1: Ok and since we're on the subject what kind of um what does he do what type what type of travelling is this?

These examples are in line with functions of the DM and as described in the literature, where it has been found to act as an elaboration marker (Fraser, 2015), and it is also commonly used to introduce questions, especially in an institutional environment such as the classroom (Heritage, 2013).

Finally, given that the DMs alright and right are comparable in their functions, the final cluster, right so, fulfils similar roles as the previously described cluster alright so. The combinations of DMs right and so are used in our corpus to focus the listeners' attention to an explanation or a summary (Examples $4 \mathrm{f}-4 \mathrm{~h}$ ).

(4f) NT3: Yeah this chemical what keeps it like though what keeps anything on a shelf the shelf life possible? Chemicals, right so it's man-made it's not natural, right?

(4g) NT1: Usually moms are nervous when they're cooking the kids are screaming around them, right so I don't know, it seems too happy for my point of view.

(4h) NT3: If you choose this topic for pro con essay you'll come back and look at this list and choose a few of them to comment on, right so they have here animal experimentation does not actually make animals suffer someone says that so please XX start us off with the letter c.

\section{Individual teachers' DM cluster use}

A closer analysis of the corpus points to the individual preferences of the participants for specific clusters, such as the already mentioned predilection of NT1 for the cluster alright so. Similarly, clusters containing the DM well are used by NT2 more frequently than the other teachers combined (26 out of the 50 occurrences in the corpus). The DM well fulfils many textual and interactional roles in speech (Müller, 2005), which makes it surprising that it is not used more by the other five teachers in our corpus. Participant NT2 used well in combination with yeah as a way to emphasize that the previous statement was in line with her expectations (Example 5a). In example 5b, it was used in combination with actually, and both of the DMs are used to introduce a selfcorrection. In this way, we can see two markers with the same function reinforcing each other. Finally, in example $5 c$, well is used in combination with alright and $o k$ as a way of conceding to the previous turn and accepting the statement and then contributing a different point of view.

(5a) NT2: Well yeah there will be nothing left ok so that's why when you have things like this (...)

(5b) NT2: (...) because you're used to the way of life here where it's very slow well actually it's not very slow it's slow, easy-going (...) 
(5c) NT2: Well alright ok you said that maybe in Croatia in Croatia it would come to a fistfight but um let's look at from a metaphorical point of view what does it suggest?

These examples show that, while NT2 used fewer DM clusters than the other native teachers, she used them skilfully to perform textual and interpersonal functions that might have been overlooked by the other participants. Another interesting example which shows teachers' personal preferences is the DM yeah which is used intensively in DM clusters by two teachers, NT3 and NNT3 (66 and 44 occurrences respectively), while all the other teachers combined used it only 38 times. This DM has also been found to be useful in the academic context with its signalling and turn-taking features (Othman, 2010). Among its other uses, yeah can be used to denote cooperation, responses and confirmation (Chapetón Castro, 2009). When it comes to its use in clusters in our corpus, NT3 used yeah in combination with I mean in six instances. In example $5 \mathrm{~d}$, yeah is used as a sign of agreement with the previous statement, while I mean introduces a further elaboration of the speaker's opinion. In Example 5e, yeah is 'sandwiched' between two occurrences of I mean. In this particular cluster, but introduces a contrasting opinion, while the two instances of I mean are used to soften the impact of this contrast and the DM yeah between them is used as a turn-keeper, a way to gain time while the speaker is considering her reply.

(5d) NT3: Yeah I mean how many do we need yeah how many the selection how many do we need in this day and time (...)

(5e) NT3: But I mean yeah I mean is it something does it help do you think those people you know who smoke does it help them through the day.

Another interesting case is the cluster in example $5 \mathrm{f}$, where the seemingly opposite DMs yeah and no co-occur, which seems unusual, but is, in fact, common and serves as a topic-shift device, changing the mood of the discourse, in our case from joking to serious (Lee-Goldman, 2011). This is why it is followed by the contrasting but and I mean once again to soften the impact of this change.

NT3: (...) to pump them up with chickens yeah no but I mean this is all we we take it all for granted.

There are several instances of clusters containing up to five DMs in our corpus, with these multiple clusters often containing repetitions, which can be taken as a sign of dysfluency of the speaker. For instance, Example $5 \mathrm{~g}$ contains DMs that are strung together to emphasize an acknowledgement of a student's reply, with the final DM and indicating that the stance of the interlocutor will be elaborated on. The other four markers were most likely uttered to gain thinking time. Similarly, in Example 5h, the teacher is emphasizing an acknowledgement of a response while giving herself time to think. She ends the sequence with the DM but to introduce a contrasting thought or a correction. 
(5g) NT3: Ok ok alright alright and it could be true, but other statistics other facts may be considered.

(5h) NT2: Alright ok ok alright but here we're not talking about the suburbs because the suburbs really like everywhere.

As opposed to the two previous examples in which markers with similar functions are clustered together, in Example 5i each of the four markers retains and performs its function adding at the same time to the overall meaning of the cluster, as required by the context. The DM yeah is used to acknowledge a comment, but introduces a contrasting statement, you know is used to soften this contrast by appealing to common knowledge and, finally, on the other hand reinforces the fact that a contrasting view follows.

NNT1: Yeah but you know on the other hand motorcyclists behave like rats when they're driving on the road (...)

To sum up, despite the similarities in the functions of the most commonly used DM clusters in the corpus, a closer examination highlights the differences between the individual teachers when it comes to their use of specific DM clusters, which most likely stem from their personal preferences.

\section{Discussion}

The analysis of our corpus has shown that DM clusters are frequently used by EFL teachers in classroom discourse, with over 700 instances of DM cluster use, out of which only 7 unique clusters were repeated more than ten times. This low number of 'fixed' or 'prototypical' combinations can be seen as evidence of the variety of possible ways in which DMs can combine, and it is also an indication of how personal preferences or linguistic habits of speakers (that is, their idiolect) influence DM cluster use. An obvious example, as described in the qualitative analysis, is the cluster alright so which was used 28 times in total, 23 of which by a single participant, NT1. The quantitative analysis of our corpus has demonstrated that native teachers utilize DM clusters significantly more frequently than their non-native counterparts, in addition to using almost three times as many unique DM clusters on average. It is interesting to note, however, that the number of unique single DMs used is almost the same for both groups, with non-native teachers even employing slightly more unique DMs than native teachers (35 and 34 different DMs on average, respectively). This would indicate that the non-native teachers were indeed familiar with the variety of DMs available for use in speech, prompting the question of why they used DM clusters at such a lower frequency and with less variety.

One possible explanation is that non-native teachers are less aware of the possibilities of using DMs in this way or less flexible in doing so. The fact that both groups used a variety of single DMs in our corpus does not necessarily imply that non-native teachers are familiar with the whole range of their potential uses or combinations. The differences between the two groups are further emphasized when it comes to the use of more than two DMs in a cluster, with non-native teachers using just a little over $10 \%$ of all such instances. Also, 
the use of repeated DMs appears to be another characteristic of native speakers' use of DM clusters, as out of the 66 such instances, only 10 can be attributed to the non-native teachers. As stated before, DM repetition is a sign of the natural disfluency which is found in the everyday speech of proficient, native speakers, and which aids instant cognitive processing, leaving the interlocutors time to plan what to say next or to choose a new orientation of discourse (Aijmer, 2004). By using fewer repetitions, non-native teachers might be missing out on this useful tool. When we look at the teachers individually, all three native teachers used more unique DM clusters than the non-native teachers, although NT2 used approximately $30 \%$ fewer unique clusters than the two other native teachers $(80$ as opposed to 121 (NT1) and 134 (NT3)), which is either a sign of individual preferences of the said teacher or indicates a different attitude towards the language used in the classroom, as will be discussed later.

DMs are specific in that they commonly perform a whole range of functions, depending on many factors such as the context or the roles of the speakers (Fuller, 2003), with Aijmer and Simon-Vandenbergen (2011) even claiming that the number of these functions could theoretically be infinite. Moreover, Svartvik (1980) pointed out that DMs belong to fine, subtle discourse-pragmatic aspects of language which are a constituent part of its socio-cultural values commonly shared by native speakers. We can, therefore, assume that, while native speakers have an inherent ability to master DMs and interpret their array of functions despite the diverse ways they can be used by different speakers (Aijmer, 2004), non-native speakers might have difficulty interpreting or using all of them. In other words, despite being aware of the variety of DMs that can be used in speech, non-native speakers seem not to be able to use them as flexibly when it comes to their combinations and repetitions. This is in line with Aijmer's (2004) findings with Swedish speakers of English as an L2, who did not use DM clusters for the same range of functions as native speakers did.

Another possible explanation lies in the potential differences between native and non-native speakers as language teachers. Reves and Medgyes (1994) mention the ability to communicate spontaneously as one of the advantages of native teachers, so it might be the case that their speech is less restrained and bears more resemblance to speech outside the classroom than the speech of non-native teachers. More natural speech leads to more disfluency and more repairs, which in turn leads to more DM clusters being used. On the other hand, as non-native teachers share an L1 with their students, they might also be more adept than native speakers at adapting their language to their students' needs. Árva and Medgyes (2000) suggest that both native and non-native speakers have their qualities as language teachers, with non-native speakers often teaching more systematically as they frequently have more pedagogic training and more understanding of their students' needs, and native speakers having the benefit of a generally higher level of linguistic competence. Therefore, it might be possible that the native teachers in this study focus less on adapting their language to their students and speak more naturally. 
Our third research question focused on the functions of the most frequent clusters in our corpus. Firstly, the qualitative analysis has found support for both views on DM clusters described in 2.2, as they are used by the teachers in our study both as combinations of DMs which each retain their meanings and functions (e.g. 5i) as well as 'empty' clusters of DMs strung together to buy time for the speaker (e.g. 5g). Furthermore, the qualitative analysis of the corpus has shown that the ten most frequent DM clusters consist of nine different individual DMs, namely ok, so, and, then, alright, right, yeah, but, yes, with so used in four of the top clusters. This demonstrates that, although there are over 300 different DM clusters in the corpus, the most common ones consist of a limited number of DMs, which are also those used most frequently in classroom discourse (Fung \& Carter, 2007). Except for the individual preference for the cluster alright so, there is not much difference between the two groups of teachers when it comes to the functions of these most frequent and, in the pedagogical setting, we might say basic DM clusters. This is hardly surprising, as the functions they perform are those of opening topics, focusing the listeners' attention, acknowledging, elaborating and modifying responses - all crucial functions for classroom discourse. These similarities can also be attributed to the constraints and limitations that the typical classroom context exerts on both teacher and student talk (see Romero-Trillo, 2002; Hellermann \& Vergun, 2007).

\section{Conclusion}

The results of the qualitative analysis of our corpus indicate that native and nonnative English teachers use the most common DM clusters to manage classroom interaction by making the transitions between activities salient and focusing the students' attention on the task, question or issue at hand. However, our quantitative analysis has shown that the classroom language use of these two groups pointedly differs when it comes to the frequency and diversity of DM clusters, DM repetitions, and clusters with multiple DMs. These differences suggest that non-native teachers lack the awareness of the variety of possibilities of combining these units. However, the intensive use of DM clusters by the native teachers might not necessarily reflect on their teacher talk positively as it may be an indication that their language in the classroom is too natural, containing features that might be undesirable in the formal classroom context where comprehensible input is still crucial to learning. Whether a higher frequency of these features might act as a discriminating factor in supporting EFL students' comprehension could only be answered by further studies focused on both teachers' and students' language use. Nevertheless, the fact is that DM clusters are pervasive in native teacher speech, and that by using them less frequently, non-native teachers might be missing out on a useful tool. The pedagogical implications of this study thus lie in highlighting the need to raise the awareness of non-native teachers of the way native speakers use DM clusters to perform a range of essential and useful functions in speech. However, further research with a much larger sample is required to make statistical generalizations. Finally, as the present paper has provided, we believe, valuable insights and findings in the field very scarcely researched so far, it will hopefully trigger further discussion and research that will involve non-native EFL teachers with different native languages. 


\section{References}

Aijmer, K. (2004). Pragmatic markers in spoken interlanguage. Nordic Journal of English Studies, 3(1), 173-190. https:/ / doi.org/10.35360/njes.29

Aijmer, K., \& Simon-Vandenbergen, A.-M. (2011). Pragmatic markers. In J. Zienkowski, J.O. Östman, \& J. Verschueren (Eds.), Discursive Pragmatics (pp. 223-247). Amsterdam, Netherlands/Philadelphia, PA: John Benjamins Publishing Company. https://doi.org/10.1075/hoph.8.13aij

Amador Moreno, C. P., O'Riordan, S., \& Chambers, A. (2006). Integrating a corpus of classroom discourse in language teacher education: the case of discourse markers. ReCALL, 18(1), 83-104. https://doi.org/10.1017/S0958344006000619

Árva, V., \& Medgyes, P. (2000). Native and non-native teachers in the classroom. System, 28(3), 355-372. https://doi.org/10.1016/S0346251X(00)00017-8

Bangerter, A., \& Clark, H. H. (2003). Navigating joint projects with dialogue. Cognitive Science, 27(2), 195-225. https://doi.org/10.1207/s15516709cog2702_3

Bortfeld, H., Leon, S. D., Bloom, J. E., Schober, M. F., \& Brennan, S. E. (2001). Disfluency rates in conversation: Effects of age, relationship, topic, role, and gender. Language and speech, 44(2), 123-147. https://doi.org/10.1177/00238309010440020101

Brinton, L. J. (1996). Pragmatic markers in English: Grammaticalization and discourse functions. Berlin, Germany: Walter de Gruyter. https:// doi.org/10.1515/9783110907582

Buysse, L. (2012). So as a multifunctional discourse marker in native and learner speech. Journal of Pragmatics, 44(3), 1764-1782. https://doi.org/10.1016/j.pragma.2012.08.012

Chapetón Castro, M. C. (2009). The Use and Functions of Discourse Markers in EFL Classroom Interaction. Profile Issues in Teachers' Professional Development, 11(1), 57-77.

Crible, L., \& Cuenca, M. J. (2017). Discourse markers in speech: characteristics and challenges for corpus annotation. Dialogue and Discourse, 8(2), 149-166. https://doi.org/10.5087/dad.2017.207

Cuenca, M. J., \& Crible, L. (2019). Co-occurrence of discourse markers in English: From juxtaposition to composition. Journal of Pragmatics, 140, 171-184. https:// doi.org/10.1016/j.pragma.2018.12.001

Cuenca, M. J., \& Marín, M. J. (2009). Co-occurrence of discourse markers in Catalan and Spanish oral narrative. Journal of Pragmatics, 41(5), 899-914. https://doi.org/10.1016/j.pragma.2008.08.010

De Klerk, V. (2005). Procedural meanings of well in a corpus of Xhosa English. Journal of Pragmatics, 37(8), 1183-1205. https:// doi.org/10.1016/j.pragma.2004.11.001

Fairbanks, B. (2016). Ojibwe discourse markers. Lincoln, NE: University of Nebraska Press. https://doi.org/10.2307/j.ctt1d4v11p

Fleischman, S., \& Yaguello, M. (2004). Discourse markers across languages. In C.L. Moder \& A. Martinovic-Zic (Eds.), Discourse across languages and cultures (pp.129-147). Amsterdam, Netherlands/Philadelphia, PA: John Benjamins Publishing Company. https:// doi.org/10.1075/slcs.68.08fle

Flowerdew, J., \& Tauroza, S. (1995). The effect of discourse markers on second language lecture comprehension. Studies in Second Language Acquisition, 17(4), 435-458. https://doi.org/10.1017/s0272263100014406

Fraser, B. (2015). The combining of discourse markers - a beginning. Journal of Pragmatics, 86, 48-53. https://doi.org/10.1016/j.pragma.2015.06.007 
Fuller, J. M. (2003). Discourse marker use across speech contexts: A comparison of native and non-native speaker performance. Multilingua, 22(2), 185-208. https://doi.org/10.1515/mult.2003.010

Fung, L., \& Carter, R. (2007). Discourse markers and spoken English: Native and learner use in pedagogic settings. Applied Linguistics, 28(3), 410-439. https://doi.org/10.1093/applin/amm030

Hellermann, J., \& Vergun, A. (2007). Language which is not taught: The discourse marker use of beginning adult learners of English. Journal of Pragmatics, 39(1), 157-179. https:// doi.org/10.1016/j.pragma.2006.04.008

Heritage, J. (2013). Turn-initial position and some of its occupants. Journal of Pragmatics, 57, 331-337. https://doi.org/10.1016/j.pragma.2013.08.025

Jung, E. H. (2006). Misunderstanding of academic monologues by nonnative speakers of English. Journal of Pragmatics, 38(11), 1928-1942. https://doi.org/10.1016/j.pragma.2005.05.001

Khazaee, H. (2012). Use of Discourse Markers by Iranian Teachers of English as a Foreign Language. Journal of Basic and Applied Scientific Research, 2(9), 8912-8917.

Lahuerta Martínez, A. C. (2004). Discourse markers in the expository writing of Spanish university students. Ibérica, 8, 63-80.

Lam, P. W. (2010). Discourse particles in corpus data and textbooks: The case of well. Applied Linguistics, 31(2), 260-281. doi:10.1093/applin/amp026

Lee-Goldman, R. (2011). No as a discourse marker. Journal of Pragmatics, 43(10), 26272649. https:// doi.org/10.1016/j.pragma.2011.03.011

Lohmann, A., \& Koops, C. (2016). In G. Kaltenböck, E. Keizer \& A. Lohman (Eds.), Outside the clause: form and function of extra-clausal consituents (pp. 417-445). Amsterdam, the Netherlands/Philadelphia, PA: John Benjamins Publishing Company. https://doi.org/10.1075/slcs.178

Maschler, Y. (2002). The role of discourse markers in the construction of multivocality in Israeli Hebrew talk in interaction. Research on Language and Social Interaction, 31(1), 1-38. https://doi.org/10.1207/s15327973rlsi35-1_1

Maschler, Y., \& Schiffrin, D. (2015). Discourse markers: Language, meaning, and context. In D. Schiffrin, D. Tannen \& H.E. Hamilton (Eds.), The handbook of discourse analysis ( $2^{\text {nd }}$ ed., pp. 189-221). Hoboken, NJ: Wiley. https://doi.org/10.1002/9781118584194.ch9

Müller, S. (2005). Discourse Markers in Native and Non-native English Discourse. Amsterdam, the Netherlands/Philadelphia, PA: John Benjamins Publishing Company. https://doi.org/10.1075/pbns.138

Othman, Z. (2010). The use of okay, right and yeah in academic lectures by native speaker lecturers: Their "anticipated" and "real" meanings. Discourse Studies, 12(5), 665-681. https://doi.org/10.1177/1461445610376365

Pons Bordería, S. (2018). The combination of discourse markers in spontaneous conversations. Revue Romane. Langue et littérature. International Journal of Romance Languages and Literatures, 53(1), 121-158. https:// doi.org/10.1075/rro.00008.pon

$\mathrm{R}$ Core Team. (2013). R: A language and environment for statistical computing. $\mathrm{R}$ Foundation for Statistical Computing [Computer software]. Vienna, Austria. Retrieved from http://www.R-project.org/.

Reves, T., \& Medgyes, P. (1994). The non-native English speaking EFL/ESL teacher's self-image: An international survey. System, 22(3), 353-367. https://doi.org/10.1016/0346-251X(94)90021-3

Romero-Trillo, J. (2002). The pragmatic fossilization of discourse markers in non-native speakers of English. Journal of Pragmatics, 34(6), 769-784. https://doi.org/10.1016/S0378-2166(02)00022-X 
Schleef, E. (2008). The "lecturer's OK" revisited: changing discourse conventions and the influence of academic division. American Speech, 83(1), 62-84. https://doi.org/10.1215/00031283-2008-003

Shahbaz, M., Sheikh, O. I., \& Ali, M. S. (2013). Use of Discourse Markers by Chinese EFL Professors: A Corpus-Based Study of Academic Lectures by Natives and Nonnatives. Journal of Education and Practice, 4(5), 80-89.

Svartvik, J. (1980). “Well” in conversation. In S. Greenbaum, G. Leech \& J. Svartvik (Eds.), Studies in English Linguistics for Randolph Quirk (pp. 167-177). Harlow, the UK: Longman.

Swan, M. (2016). Practical English Usage (4th ed). Oxford, England: Oxford University Press.

Thornbury, S., \& Slade D. (2006). Conversation: From Description to Pedagogy. Cambridge, England: Cambridge University Press. https:// doi.org/10.1017/CBO9780511733123

Vickov, G., \& Jakupčević, E. (2017). Discourse Markers in Non-Native EFL Teacher Talk. Studies in Second Language Learning and Teaching, 7(4), 649-671. doi:10.14746/ssllt.2017.7.4.5

Walsh, S. (2006). Investigating Classroom Discourse. London, England: Routledge. https://doi.org/10.4324/9780203015711

Walsh, S. (2013). Classroom discourse and teacher development. Edinburgh, Scotland: Edinburgh University Press. 